Parasitology

\title{
The role of glycosylated epitopes in the serodiagnosis of Strongyloides stercoralis infection论，论标，
}

\author{
Elizabete de Jesus Inês, Mônica Lopes Sampaio Silva, Joelma Nascimento Souza, \\ Márcia Cristina Aquino Teixeira, Neci Matos Soares* \\ Departamento de Análises Clínicas e Toxicológicas, Faculdade de Farmácia, Universidade Federal da Bahia, 40170-115, Salvador, Bahia, Brazil
}

\section{A R T I C L E I N F O}

\section{Article history:}

Received 20 November 2012

Received in revised form 3 January 2013

Accepted 15 January 2013

Available online 27 March 2013

\section{Keywords:}

Strongyloides stercoralis

Sodium metaperiodate

Serodiagnosis

Glycoproteins

\begin{abstract}
A B S T R A C T
Carbohydrates of pathogen antigens have been disrupted by periodate oxidation, in order to reduce nonspecific bindings and improve serodiagnosis of parasite infections. In the present study, the enzymelinked immunosorbent assay (ELISA) was carried out with filariform larvae antigen treated, or not treated, with sodium metaperiodate. Groups of sera from patients with Strongyloides stercoralis infection, with other intestinal parasites and a normal control, were used. The oxidation of Strongyloides stercoralis glycosylated epitopes reduced the seroreactivity of sera from patients with $S$. stercoralis infection as demonstrated by ELISA, with a decrease in sera optical densities. The number of cross-reactions of IgG and IgE-ELISAs increased by $12 \%$ and $16 \%$, respectively, after antigen treatment with metaperiodate. This was more often observed in patients infected with Schistosoma mansoni and hookworm. Moreover, the IgG depletion from sera tested by IgE-ELISA led to the detection of previous false-negative samples from S. stercoralis-infected patients.
\end{abstract}

(c) 2013 Elsevier Inc. All rights reserved.

\section{Introduction}

Strongyloides stercoralis is widely distributed in tropical and subtropical regions, and it is estimated that approximately 35 million people are infected worldwide, with frequencies above 6\% in Brazil (De Bona and Basso, 2008; Inês et al., 2011; Kothbary et al., 1999; Oliveira et al., 2002; Olsen et al., 2009). S. stercoralis infection in immunocompetent patients usually results in asymptomatic chronic disease. Nevertheless, hyperinfection and dissemination can occur in high-risk groups, such as patients undergoing glucocorticoid therapy; those with hematologic malignancy; those co-infected with human Tlymphotropic virus type I (HTLV-1) and HIV; and those suffering from chronic alcohol abuse (reviewed by Keiser and Nutman, 2004). The diagnosis of $S$. stercoralis infection usually relies on the detection of larvae in stool samples. The majority of cases involve a chronic infection with an intermittent and small larvae load in the feces, and a decrease in the sensitivity of parasitologic tests. It has been recommended that at least 4 negative results for stool examinations

\footnotetext{
This paper was presented in part at the XVIII International Congress for Tropical Medicine and Malaria and at the XLVIII Congress of the Brazilian Society of Tropical Medicine.

站放 Potential conflicts of interest: The authors declare that they have no competing financial interests.

$\star$ This study was supported by Fundação de Amparo à Pesquisa do Estado da Bahia (FAPESB), Brazil. The experiments comply with the currents laws of Brazil.

* Corresponding author. Tel.: +55-71-32836950; fax: +55-71-32836919.

E-mail address: necisoares@gmail.com (N.M. Soares).
}

are required to rule out the Strongyloides stercoralis infection (Dreyer et al., 1996; Liu and Weller, 1993; Roxby et al., 2009; Uparanukraw et al., 1999). Stool culture in agar plate has been shown to be a more sensitive diagnostic tool than the Baermann-Moraes technique, although it is more laborious and time consuming (Inês et al., 2011; Jongwutiwes et al., 1999; Koga et al., 1992). To bypass the limitations of parasitologic methods, an enzyme-linked immunosorbent assay (ELISA), to detect IgG anti-S. stercoralis, has been used. Nevertheless, the cross-reactivity with other intestinal helminths overestimates the true prevalence of $S$. stercoralis infection and represents a great limitation to serologic assays (Costa-Cruz et al., 2003; Dreyer et al., 1996; Uparanukraw et al., 1999). The demonstration of specific IgE response in human strongyloidiasis by ELISA has been used for diagnosis, since the cross-reactivities with other helminthes are lower than those reactions with specific IgG. In spite of this, IgE anti-S. stercoralis may not be detected by ELISA due to the presence of excessive amounts of circulating IgG which produces a competitive inhibition of IgE binding sites (Costa-Cruz et al., 2003; Leoratti, 2004). Moreover, patients under steroid therapy or coinfected with $S$. stercoralis and HTLV may have lower circulating specific IgE (Machado et al., 2011; Porto et al., 2001).

Previous studies have shown that a specific antibody reactivity with glycoproteins of pathogen antigens was improved after periodate oxidation of their glycosylated epitopes at acid pH (Alarcón de Noya et al., 2000; Albuquerque et al., 2005; Kouguchi et al., 2011). The disruption of carbohydrates from Schistosoma mansoni egg soluble antigen increased the specificity of schistosomiasis immunodiagnosis 
(Alarcón de Noya et al., 2000; Noya et al., 2002) and allowed the discrimination between the chronic and acute forms of paracoccidiomycosis by using a carbohydrate-modified antigenic preparation to test the reactivity towards IgG and IgM (Ferreira et al., 2008). On the other hand, with visceral leishmaniasis, the metaperiodate treatment of Leishmania infantum/chagasi antigens resulted in a reduction of the seroreactivity by ELISA (Atta et al., 2004).

In the present study, we describe, for the first time to our knowledge, an ELISA for detection of Strongyloides stercoralis $\operatorname{IgG}$ and IgE antibodies using parasite soluble antigens treated with sodium metaperiodate to remove the glycosylated molecules. Furthermore, the efficacy of previous depletion of IgG from the sera of S. stercoralisinfected patients for detection of IgE reactivity was evaluated.

\section{Materials and methods}

\subsection{Patients and sera samples}

The present study was carried out from November 2009 to December 2010 on individuals seen at the Clinical Analysis Laboratory of Pharmacia College, Federal University of Bahia, Brazil. Daily, around 2-3 sera samples from patients were randomly selected according to the coproparasitologic results of spontaneous sedimentation, Baermann-Moraes method, and agar plate culture methods. A total of 100 sera samples from parasitized individuals consisting of 50 from $S$. stercoralis monoinfected patients and 50 with other intestinal parasites, including hookworm (10), Ascaris lumbricoides (9) Schistosoma mansoni (10), Trichuris trichiura (10), Enterobius vermicularis (2), and Trichostrongylus sp. (9) were used to perform the ELISA for detection of Strongyloides-specific IgG and IgE. As negative controls, 34 sera samples from newborns of mothers with negative parasitologic test results and 14 from healthy adults, who were members of the laboratory staff, were used. False IgE-negative results from patients shedding $S$. stercoralis larvae in feces were evaluated in 10 IgG-depleted samples.

This study was approved by the Committee of Ethics in Research of the Gonçalo Moniz Institute, Oswaldo Cruz Foundation, and an informed consent for participation was obtained from each patient during delivery of clinical specimens.

\subsection{Strongyloides stercoralis soluble antigen}

Strongyloides stercoralis soluble antigen ( $\mathrm{SsAg}$ ) was prepared as described previously (Arakaki et al., 1990). Briefly, S. stercoralis filariform larvae were obtained from feces culture of hyperinfected patients. Larvae were washed 5 times in $0.15 \mathrm{~mol} / \mathrm{L}$ of phosphatebuffered saline (PBS, pH 7.2) by centrifuging for $7 \mathrm{~min}$ at $1.8 \times \mathrm{g}$. Parasites were suspended for 5 min in $0.25 \%$ sodium hypochlorite and then washed 5 times in PBS as described above. The larvae were suspended in PBS with protease inhibitors ( $5 \mathrm{mmol} / \mathrm{L}$ EDTA, $1 \mathrm{mmol} / \mathrm{L}$ phenyl-methylsulfonylfluoride [Sigma], $0.05 \mathrm{mmol} / \mathrm{L}$ TPCK/TLCK, $1 \mu \mathrm{g} / \mathrm{mL}$ leupeptin) and sonicated in an ice bath for a duration of 9 cycles of $80 \mathrm{~s}$ at $40 \mathrm{kHz}$ (Branson Sonifier Cell Disruptor, Branson Instruments, Danbury, CT, USA). The larvae homogenate was then centrifuged at $11,000 \times \mathrm{g}$ for $30 \mathrm{~min}$ at $4{ }^{\circ} \mathrm{C}$. The supernatant with soluble antigen was analyzed for protein content according to Lowry et al. (1951), divided into aliquots, and stored at $-70{ }^{\circ} \mathrm{C}$ until use.

\subsection{IgG-depleted sera}

IgG depletion from human serum was carried with rheumatoid factor (RF) absorbent according to the manufacturer's instructions (Siemens, Marburg, Germany). Briefly, sera samples were diluted 1:4 in PBS-0.05\% Tween-20 and 1\% BSA followed by a new 1:2 dilution in $\mathrm{RF}$ absorbent. Samples were well mixed, incubated for $18 \mathrm{~h}$ at $4{ }^{\circ} \mathrm{C}$, and then centrifuged for $5 \mathrm{~min}$ at $1.8 \times \mathrm{g}$. The supernatant was used to perform the immunoassay to detect specific IgE.

\subsection{Enzyme-linked immunosorbent assay for $\operatorname{IgG}$ and $\operatorname{IgE}$ detection}

Indirect ELISA for specific IgG and IgE was conducted as previously described by Van Doorn et al. (2007) with some modifications. Briefly, the microtiter plates (Corning Costar polystyrene EIA/RIA plates, Corning) were coated with $10 \mu \mathrm{g} / \mathrm{mL}$ of $S$. stercoralis antigen in 0.06 $\mathrm{mol} / \mathrm{L}$ carbonate-bicarbonate buffer ( $\mathrm{pH} 9.6$ ), incubated overnight at $4{ }^{\circ} \mathrm{C}$, and washed 3 times with PBS containing 0.05\% Tween-20 (PBS$\mathrm{T})$. To test the role of glycosylated epitopes, the SsAg was treated with sodium metaperiodate (MSsAg) according to Woodward et al. (1985). Soon thereafter, SsAg-coated plates, as described above, were washed with $50 \mathrm{mmol} / \mathrm{L}$ sodium acetate buffer ( $\mathrm{pH} 4.5$ ) and then glycosylated epitopes were oxidated by the addition of $100 \mu \mathrm{L}$ of $10 \mathrm{mmol} / \mathrm{L}$ sodium metaperiodate in $50 \mathrm{~m} \mathrm{mmol} / \mathrm{L}$ sodium acetate buffer ( $\mathrm{pH} 4.5)$. Plates were then incubated for $1 \mathrm{~h}$ at room temperature in the absence of light, washed 3 times with PBS ( $\mathrm{pH} 7.2$ ), and incubated with $100 \mu \mathrm{L}$ of $50 \mathrm{mmol} / \mathrm{L}$ sodium borohydride in PBS for $30 \mathrm{~min}$ at room temperature, followed by rinsing with $50 \mathrm{mmol} / \mathrm{L}$ sodium acetate buffer ( $\mathrm{pH} 4.5$ ). MSsAg- and SsAg-coated plates were blocked with $100 \mu \mathrm{L}$ PBS-T plus 5\% w/v skim milk (PBS-T-Milk) or with PBS-T plus $1 \% \mathrm{w} / \mathrm{v}$ bovine serum albumin (PBS-T-BSA) for $1 \mathrm{~h}$ at $37{ }^{\circ} \mathrm{C}$ for $S$. stercoralis IgG and IgE detection by ELISA, respectively. After blocking, wells were washed as described previously.

Assays for specific IgG antibodies were performed with sera samples diluted at 1:100. Plates coated with MSsAg or SsAg were incubated in duplicate with $100 \mu \mathrm{L}$ of sera per well for $1 \mathrm{~h}$ at $37{ }^{\circ} \mathrm{C}$. Thereafter, $100 \mu \mathrm{L}$ of conjugated anti-human IgG linked to horseradish peroxidase (Sigma-Aldrich, St. Louis, MO, USA) diluted at 1:4000 was added and incubated in the same conditions. The reaction was revealed by the addition of $100 \mu \mathrm{L}$ of substrate $(100 \mu \mathrm{L}$ of $0.051 \mathrm{~mol} / \mathrm{L}$ citrate-phosphate buffer [ $\mathrm{pH} 5.0]$ containing $0.0037 \mathrm{~mol} / \mathrm{L} p$-phenylenediamine and $0.04 \%$ hydrogen peroxide 30 volumes) and incubated for a period of $20 \mathrm{~min}$ in the absence of light, followed by the addition of $20 \mu \mathrm{L}$ of $8 \mathrm{~N}$ sulfuric acid to stop the reaction. The absorbance (Abs) was measured at 450-630 nm with a microplate reader (Awareness Technology, USA).

Assays for specific IgE antibodies were carried out using whole or IgG-depleted sera as discussed in Section 2.3. To each well coated with MSsAg or SsAg, $100 \mu \mathrm{L}$ of 1:8 dilution of sera samples was added (depleted or undepleted of $\operatorname{IgG}$ ) and incubated for $1 \mathrm{~h}$ at room temperature. The wells were washed 3 times with PBS-T, and $100 \mu \mathrm{L}$ of biotinylated goat anti-human IgE (Kirkegaard \& Perry Laboratories, Gaithersburg, MD, USA) diluted 1:2000 was added. After incubation for $1 \mathrm{~h}$ at room temperature, the wells were washed as described

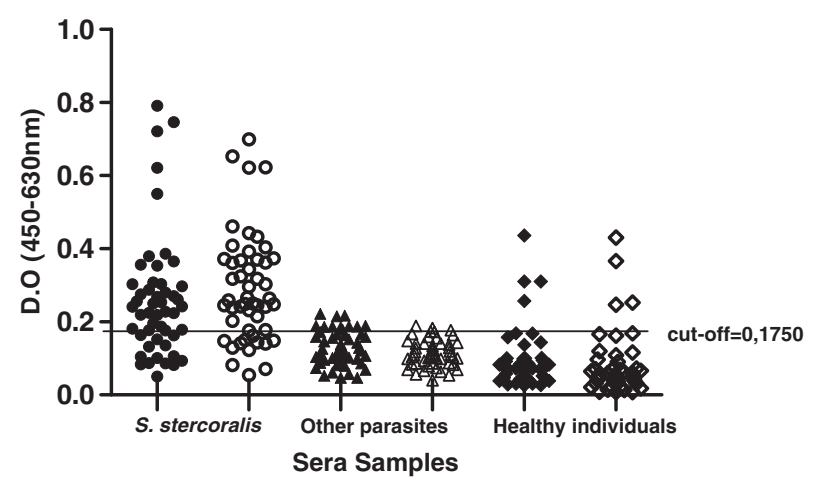

Fig. 1. Indirect ELISA to detect IgG anti-S. stercoralis using S. stercoralis soluble antigens treated with sodium metaperiodate (black symbols) and without treatment (hollow symbols). Sera samples from infected patients with S. stercoralis $(n=50)$ or with other intestinal parasites $(n=50)$ and from healthy individuals $(n=48)$ were tested. The cut-off was calculated by the ROC curve. 
Table 1

ELISA for detection of IgG and IgE antibodies using S. stercoralis soluble antigen treated with sodium metaperiodate (MSsAg) and without treatment ( $\mathrm{SsAg}$ ).

\begin{tabular}{|c|c|c|c|c|c|}
\hline \multicolumn{6}{|c|}{ Cross-reactions with other intestinal parasitic infections } \\
\hline \multirow[t]{3}{*}{ anfections } & \multirow{3}{*}{$\begin{array}{l}\text { No. of sera } \\
\text { tested }\end{array}$} & \multicolumn{2}{|l|}{ IgG-ELISA } & \multicolumn{2}{|l|}{ IgE-ELISA } \\
\hline & & MSsAg & SsAg & MSsAg & SsAg \\
\hline & & \multicolumn{2}{|c|}{$\begin{array}{l}\text { No. (\%) of positive } \\
\text { samples }\end{array}$} & \multicolumn{2}{|c|}{$\begin{array}{l}\text { No. (\%) of positive } \\
\text { samples }\end{array}$} \\
\hline Schistosoma mansoni & 10 & $5(50 \%)$ & $2(20 \%)$ & $7(70 \%)$ & $5(50 \%)$ \\
\hline Hookworm & 10 & $3(30 \%)$ & $2(20 \%)$ & $6(60 \%)$ & $4(40 \%)$ \\
\hline Trichuris trichiura & 10 & $1(10 \%)$ & $1(10 \%)$ & $6(60 \%)$ & $2(20 \%)$ \\
\hline Trichostrongylus sp. & 9 & $1(11.1 \%)$ & $0(0 \%)$ & $1(11.1 \%)$ & $1(11.1 \%)$ \\
\hline Ascaris lumbricoides & 9 & $1(11.1 \%)$ & $0(0 \%)$ & $3(33.3 \%)$ & $3(33.3 \%)$ \\
\hline $\begin{array}{l}\text { Enterobius } \\
\quad \text { vermicularis }\end{array}$ & 2 & $0(0 \%)$ & $0(0 \%)$ & $0(0 \%)$ & $0(0 \%)$ \\
\hline Total & 50 & $11(22 \%)$ & $5(10 \%)$ & $23(46 \%)$ & $15(30 \%)$ \\
\hline
\end{tabular}

a Infected patients with only 1 parasite specie.

previously. The reaction was amplified by adding $100 \mu \mathrm{L}$ of streptavidin-peroxidase conjugate (Kirkegaard \& Perry Laboratories) diluted at $1: 500$, followed by a 30 -min incubation at room temperature. Plates were washed, and the reactions were revealed by adding the enzyme substrate 2,2'-azino-bis-3 ethyl-benzothiazoline sulfonic acid (ABTS $®, 0.01 \mathrm{~mol} / \mathrm{L}$ ) (Kirkegaard \& Perry Laboratories) and incubated for a period of $30 \mathrm{~min}$ in the absence of light. The absorbance was read at $405 \mathrm{~nm}$.

\subsection{Data analysis}

Statistical analysis was performed using the software GraphPad Prism version 5.0 (GraphPad Software, San Diego, CA, USA). The cutoff value, sensitivity, and specificity were established by receiver operating characteristic (ROC) curve analysis using, as negative control, 48 sample sera from healthy individuals and 50 from patients with other intestinal parasites. The comparison among the sera groups was carried out using analysis of variance test followed by Dunn's test. The different mean optical densities obtained by ELISA using antigen treated with sodium metaperiodate and without treatment were analyzed by paired $t$ test. Differences were considered as statistically significant when $P<0.05$.

\section{Results}

\subsection{Specific IgG and IgE detection by ELISA}

The assays performed to detect specific $\operatorname{IgG}$ from sera of $S$. stercoralis infected patients using MSsAg and SsAg demonstrated

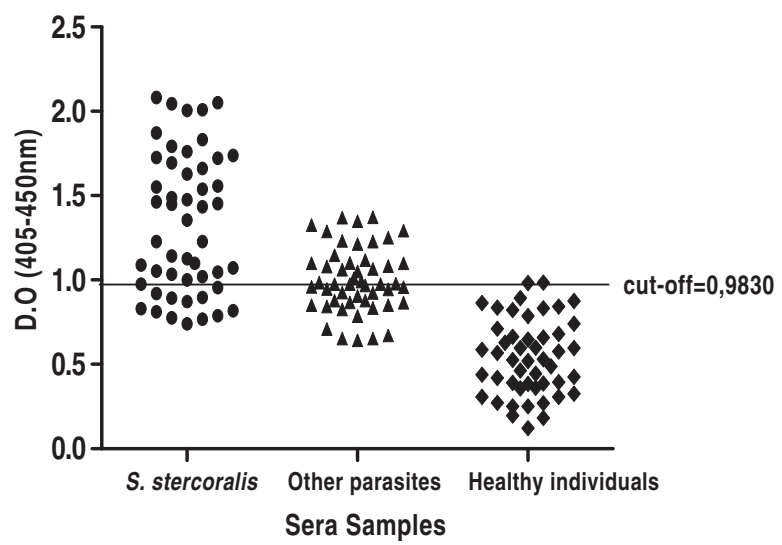

reactivity in $36(72 \%)$ and 38 (76\%) out of 50 cases, respectively (Fig. 1). The results showed no significant differences between assays $(P>0.05)$, although the IgG-ELISA mean optical densities of sera using MSsAg were lower $(0.26 \pm 0.17)$ than when SsAg was used $(0.29 \pm$ $0.15)(P<0.05)$. IgG-ELISA cross-reactivity was found in $11(22 \%)$, using MSsAg, and in 5 (10\%), using SsAg, out of 50 sera from patients infected with other intestinal parasites (Table 1). Sera from Schistosoma mansoni and from hookworm-infected patients showed a higher number of cross-reactions (Table 1 ). The specificities of IgGELISA using MSsAg and SsAg were 83.7\% and 92.9\%, respectively ( $P<$ 0.05) (Fig. 3).

The ELISAs for specific IgE from sera of S. stercoralis-infected patients using MSsAg and SsAg showed seroreactivity in 37 (74\%) and $40(80 \%)$ of 50 samples, respectively, without significant differences between assays $(P>0.05)$ (Fig. 2$)$. The presence of cross-reactivity with MSsAg was 46\% (23/50) and 30\% (15/50) with SsAg (Fig. 2). IgE assays also produced a higher number of cross-reactions with sera from Schistosoma mansoni and hookworm-infected patients (Table 1). The specificity of IgE-ELISA was significantly different using MSsAg (75.5\%) compared to the assay with SsAg (90.8\%) $(P<0.05)$ (Fig. 3).

To test the IgG competition for IgE Strongyloides antigen binding sites, the IgE reactivity was assessed in $10 \mathrm{IgE}$ false-negative sera from parasitologically confirmed S. stercoralis-infected patients, after the IgG absorption. IgG-depleted sera were accompanied by a significant increase in seroreactivity of these sera as shown in Fig. $4(P<0.05)$.

\section{Discussion}

Many parasitologic techniques have been evaluated to detect $S$. stercoralis infection. However, S. stercoralis is one of the most difficult intestinal parasites to diagnose due to the low parasite load and irregular larvae output in the majority of subclinical infections (Hirata et al., 2007; Inês et al., 2011). Immunoassays to measure antibodies have been applied to diagnose infectious diseases, including those caused by parasites, because of their high detection power and ease of implementation (Schaffel et al., 2001; Van Doorn et al., 2007). Unfortunately, the presence of cross-reactions, especially in regions with high prevalence of intestinal parasites, is very frequent. Moreover, the constant exposure of patients to S. stercoralis and maintenance of a low-parasite-load infection, not always detected by parasitologic methods, may also affect the sensitivity and specificity of immunoassays.

The development of immunologic methods using modified or purified parasite antigens could improve the sensitivity and specificity of serodiagnostic methods for S. stercoralis infection. In fact, parasite nematodes express many unusual complex carbohydrates at the cell surface in the form of glycoconjugates and glycol phospholipids. The

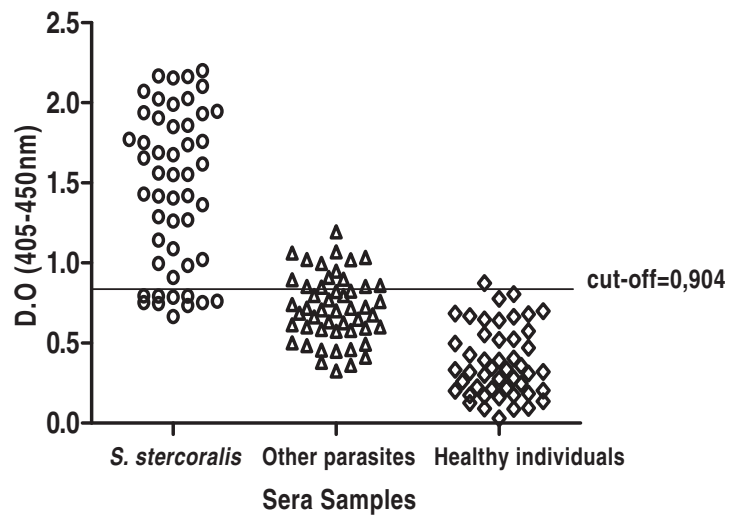

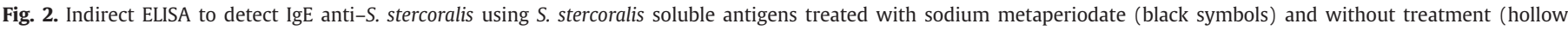

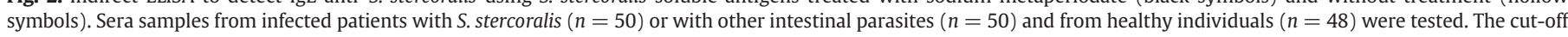
was calculated by the ROC curve. 

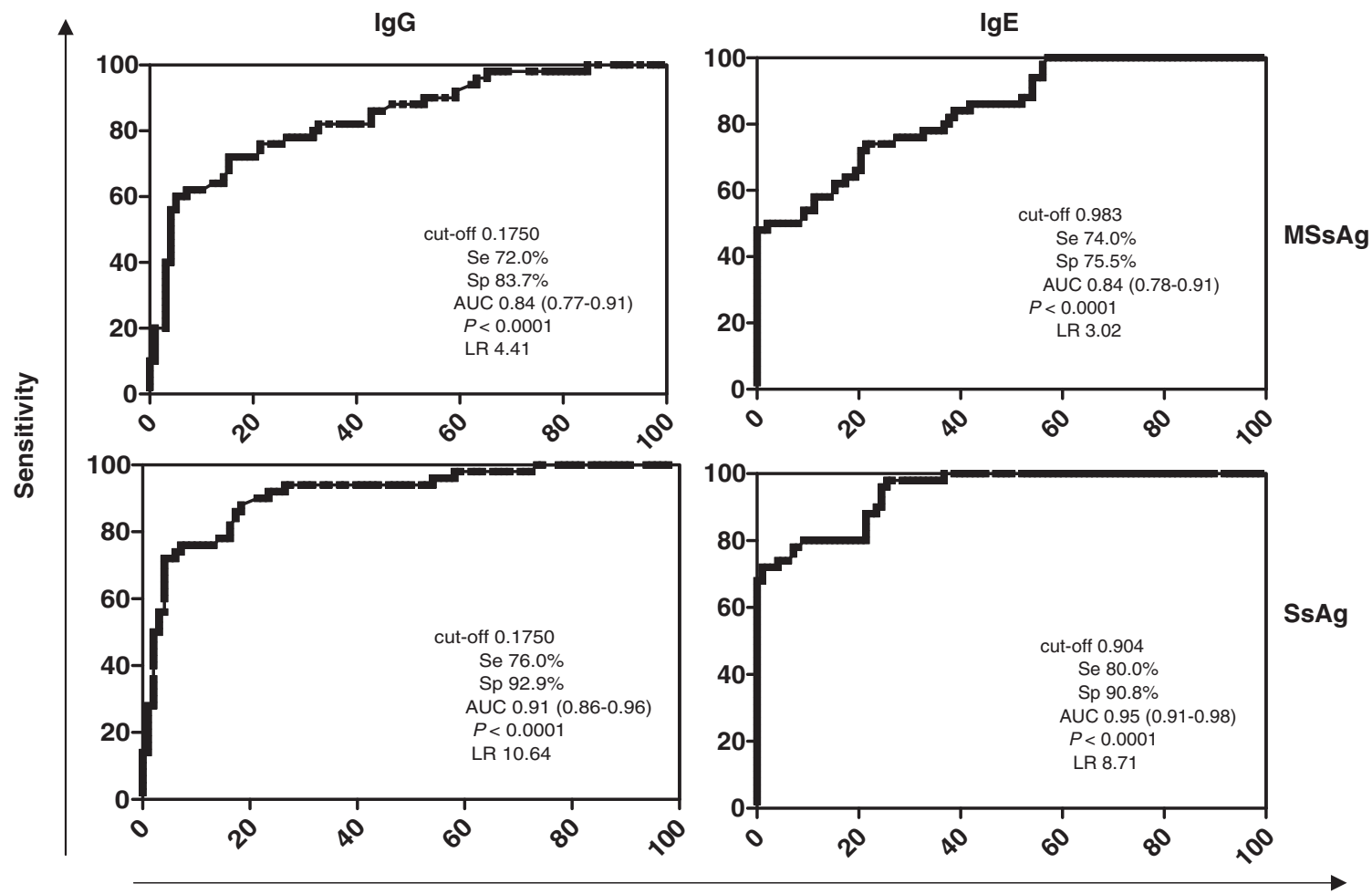

1 - specificity

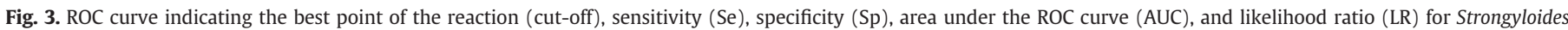
stercoralis soluble antigen treated with sodium metaperiodate (MSsAg) and without sodium metaperiodate treatment (SsAg) in sera samples for IgG and IgE detection.

cuticle surface of several nematode species is covered by a carbohydrate-rich glycocalyx that can be secreted and excreted as glycoconjugate antigens (Gonzaga, 2011; Maruyama et al., 2000). In several cases, such molecules have been shown to be involved in parasite survival, infection, and specific recognition by cells (Maruyama et al., 2000; Obregón-Henao et al., 2001; Schallig and Van Leeuwen, 1996).

The role of glycoprotein epitopes in increased antigenicity has been demonstrated in immunoassays to detect parasite antibodies (Alarcón de Noya et al., 2000; Kouguchi et al., 2011). Mild periodate oxidation destroys carbohydrates without altering protein and lipid epitopes and has been used to evaluate the carbohydrate role of antigenic glycoproteins in seroreactivity (Feizi and Childs, 1987). As shown here, for the first time, antibody reactivity to $S$. stercoralis was increased in the presence of glycosylated epitopes, thereby the sensitivity of ELISA with antigen treatment with sodium metaperiodate decreased from $76 \%$ to $72 \%$ for $\operatorname{IgG}$ and from $80 \%$ to $74 \%$ for $\operatorname{IgE}$.

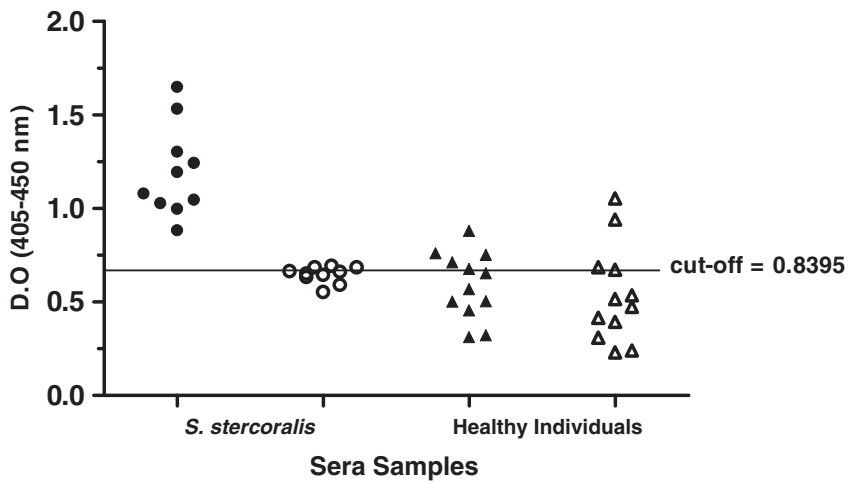

Fig. 4. Indirect ELISA to detect IgE anti-S. stercoralis using IgG-depleted (black symbols) and undepleted sera (hollow symbols). The cut-off was calculated by the ROC curve.
The mean optical densities of positive sera for S. stercoralis also decreased significantly in IgG immunoassays when the carbohydrate molecules were disrupted. These findings suggest a reduction of specific immunoreactivity when glycosylated epitopes are removed from parasite antigens, as previously demonstrated in immunoassays with sera from patients infected with Hemonchus contortus (Schallig and Van Leeuwen, 1996; Vervelde et al., 2003), Taenia solium (Obregón-Henao et al., 2001), and Leishmania (Atta et al., 2004).

Glycoprotein antigens are also associated with cross-reactions in immunodiagnostic tests, as observed previously in human sera from patients infected with Schistosoma mansoni (Alarcón de Noya et al. 2000), Leishmania sp. (Gomes-Silva et al., 2008), and Echinococcos granulosus (Kanwar and Vinayak, 1993; Younis et al., 2008). On the other hand, in the present study, the depletion of glycosylated epitopes from $S$. stercoralis antigens increased the cross-reactions with other parasites from $10 \%$ to $22 \%$ in IgG and from $30 \%$ to $46 \%$ in IgE ELISAs, thereby the specificity of both $\operatorname{IgG}$ and $\operatorname{IgE}$ assays decreased after carbohydrate depletion. These results are in agreement with those published by Albuquerque et al. (2005) who reported higher cross-reactivity by ELISA with Paracoccidioides brasiliensis antigen in the absence of glycosylated epitopes. The high level of cross-reactions after depletion of glycosylated epitopes may be associated with exposure of nonspecific antigenic binding sites hidden by carbohydrates. These results may also suggest that lectin-binding specific sites are present in $S$. stercoralis soluble antigens.

Circulating specific IgE may be a marker to distinguish current parasite infection from a past infection. In addition, IgE-ELISA has shown higher specificity than IgG-ELISA, presenting few crossreactions with other intestinal parasites (Conway et al., 1993; CostaCruz et al., 2003). In this work, the conventional IgE-ELISA showed sensitivity and specificity of $80 \%$ and $90.8 \%$, respectively. This is in agreement with other studies of the detection of IgE anti-S. stercoralis (Conway et al., 1993; Neva et al., 1981; Schaffel et al., 2001; Uparanukraw et al., 1999). However, there was no reduction in 
cross-reactions in IgE-ELISA compared to IgG-ELISA, which may be explained by the constant exposition of the patients to $S$. stercoralis infection and by the maintenance of a low parasite load undetectable by parasitologic methods, but with detectable IgE specific antibodies. The absorption of serum samples with other helminth antigens has also been used to reduce the cross-reactivity in serologic tests (Conway et al., 1993). Nevertheless, difficulties in obtaining antigens from various parasite species, often requiring experimental models, make this approach unfeasible for immunodiagnosis. The depletion of IgG may increase the sensitivity of diagnostic tests, avoiding competition for the same IgE-antigen binding site (Rihet et al., 1992) as demonstrated in an immunoassay to detect IgE antiLeishmania (Souza-Atta et al., 1999) and anti-Paracoccidioides (Mamoni et al., 2001). In the present study, 20\% (10/50) of sera from patients with $S$. stercoralis-confirmed infection by parasitologic diagnoses presented false-negative results in IgE-ELISA. This fact can be attributed to low levels of specific circulating IgE antibodies, which hampers detection by serologic assays. Moreover, in disseminated strongyloidiasis, patients often have low levels of circulating IgE (Atkins et al., 1998; Hayashi et al., 1997; Porto et al., 2001). In conclusion, the results presented in this study show a decrease in the sensitivity and specificity of ELISA for IgG and IgE detection in the absence of $S$. stercoralis glycosylated epitopes. Additionally, previous absorption of IgG from patients' sera improved the sensitivity of ELISA for IgE anti-S. stercoralis, increasing the number of infected patients diagnosed.

\section{References}

Alarcón de Noya B, Colmenares C, Lanz H, Caracciolo MA, Losada S, Noya O. Schistosoma mansoni: immunodiagnosis is improved by sodium metaperiodate which reduces cross-reactivity due to glycosylated epitopes of soluble egg antigen. Exp Parasitol 2000;95:106-12.

Albuquerque CF, Marques SH, Camargo ZP. Improvement of the specificity of an ELISA linked immunosorbent assay for diagnosis of paracoccidioidomycosis. J Clin Microbiol 2005;43:1944-6.

Arakaki T, Iwanaga M, Kinjo F, Saito A, Asato R, Ikeshiro T. Efficacy of agar-plate culture in detection of Strongyloides stercoralis infection. J Parasitol 1990;76:425-8.

Atkins NS, Lindo JF, Lee MG, Hanchard B, Robinson RD, Bundy DA. Immunomodulatory effects of concurrent HTLV-I infection in strongyloidiasis. J Acquir Immune Defic Syndr Hum Retrovirol 1998;18:188-90.

Atta AM, Colossi R, Sousa-Atta ML, Jeronimo SM, Nascimento MD, Bezerra GF, et al. Antileishmanial $\operatorname{IgG}$ and IgE antibodies recognize predominantly carbohydrate epitopes of glycosylated antigens in visceral leishmaniasis. Mem Inst Oswaldo Cruz 2004;99:525-30.

Conway DJ, Atkins NS, Lillywhite JE, Bailey JW, Robinson RD, Lindo JF, et al. Immunodiagnosis of Strongyloides stercoralis infection: a method for increasing the specificity of the indirect ELISA. Trans R Soc Trop Med Hyg 1993;87:173-6.

Costa-Cruz JM, Madalena J, Silva DAO, Sopelete MC, Campos DMB, Taketomi EA. Heterologous antigen extracts in ELISA for the detection of human IgE antiStrongyloides stercoralis. Rev Inst Med Trop São Paulo 2003;45:265-8.

De Bona S, Basso RMC. Hyperinfection by Strongyloides stercoralis associated with chronic use of corticosteroid. Rev Bras Anal Clin 2008;40:247-50.

Dreyer G, Fernandes-Silva E, Alves S, Rocha A, Albuquerque R, Addiss D. Patterns of detection of Strongyloides stercoralis in stool specimens: implications for diagnosis and clinical trials. J Clin Microbiol 1996;34:2569-71.

Feizi T, Childs RA. Carbohydrates as antigenic determinants of glycoproteins. Biochem J 1987;245:1-11.

Ferreira AP, Côrrea T, Cunha R, Marques MJ, Montesano MA, Souza MA, et al. Human serum antibody reactivity towards Paracoccidioides brasiliensis antigens treated with sodium metaperiodate. Rev Soc Bras Med Trop 2008;41:325-9.

Gomes-Silva A, Souza MA, Afonso-Cardoso SR, Andrade LR, Dietze R, Lemos E, et al. Serological reactivity of different antigenic preparations of Leishmania (Leishmania) amazonensis and the Leishmania braziliensis complex. Rev Soc Bras Med Trop 2008:41:135-41.

Gonzaga HT. Reatividade de anticorpos a frações antigênicas de Strongyloides venezuelensis no diagnóstico diferencial da estrongiloidíase humana. Dissertação (Mestrado) - Instituto de Ciências Biomédicas, Universidade Federal de Uberlândia, 2011.

Hayashi J, Kishihara Y, Yoshimura E, Furusyo N, Yamaji K, Kawakami Y, et al. Correlation between human $\mathrm{T}$ cell lymphotropic virus type-1 and Strongyloides stercoralis infections and serum immunoglobulin E responses in residents of Okinawa, Japan. Am J Trop Med Hyg 1997;56:71-5.
Hirata T, Nakamura H, Kinjo N, Hokama A, Kinjo F. Increased detection rate of Strongyloides stercoralis by repeated stool examinations using the agar plate culture method. Am J Trop Med Hyg 2007;77:683-4.

Inês EJ, Souza JN, Santos RC, Souza ES, Santos FL, Silva MLS, et al. Efficacy of parasitological methods for the diagnosis of Strongyloides stercoralis and hookworm in faecal specimens. Acta Trop 2011;120:206-10.

Jongwutiwes S, Charoenkorn M, Sitthichareonchai P, Akaraborvorn P, Putaporntip C. Increased sensitivity of routine laboratory detection of Strongyloides stercoralis and hookworm by agar-plate culture. Trans R Soc Trop Med Hyg 1999;93:398-400.

Kanwar JR, Vinayak VK. Isolation \& immunochemical characterization of diagnostically relevant antigens of Echinococcus gramulosus. Indian J Med Res 1993;97:75-82.

Keiser PB, Nutman TB. Strongyloides stercoralis in the immunocompromised population. Clin Microbiol Rev 2004;17:208-17.

Koga K, Kasuya S, Ohtom H. How effective is the agar plate method for Strongyloides stercoralis? J Parasitol 1992;78:155-6.

Kothbary NN, Muskie JM, Matbur SC. Residents' Teaching Files: Strongyloides stercoralis hyperinfection. Radiographics 1999;19:1077-81.

Kouguchi H, Matsumoto J, Yamano K, Katoh Y, Oku Y, Suzuki T, et al. Echinococcus multilocularis: purification and characterization of glycoprotein antigens with serodiagnostic potential for canine infection. Exp Parasitol 2011;128:50-6.

Leoratti FMS. Resposta imune humoral na malária humana: quantidade e qualidade de anticorpos anti-Plasmodium falciparum. Dissertação (Mestrado) - Faculdade de Medicina, Universidade de São Paulo, 2004.

Liu LX, Weller PF. Strongyloidiasis and other intestinal nematode infections. Infect Dis Clin N Am 1993;37:655-82.

Lowry OH, Rosebrough NJ, Farr AL, Randall RJ. Protein measurement with the folin phenol reagent. J Biol Chem 1951;193:265-75.

Machado ER, Carlos D, Sorgi CA, Ramos SG, Souza DI, Soares EG, et al. Dexamethasone effects in the Strongyloides venezuelensis infection in a murine model. Am J Trop Med Hyg 2011;84:957-66.

Mamoni RL, Rossi CL, Camargo ZP, Blotta MHSL. Capture enzyme-linked immunosorbent assay to detect specific immunoglobulin $\mathrm{E}$ in sera of patients with paracoccidioidomycosis. Am J Trop Med Hyg 2001;65:237-41.

Maruyama H, Yabu Y, Yoshida A, Nawa Y, Ohta N. A role of mast cell glycosaminoglycans for the immunological expulsion of intestinal nematode, Strongyloides venezuelensis. J Immunol 2000;164:3749-59.

Neva FA, Gam AA, Burke J. Comparison of larval antigens in an enzyme-linked immunosorbent assay for strongyloidiasis in humans. J Infect Dis 1981;144: 427-32.

Noya O, Alarcón de Noya B, Losada S, Colmenares C, Guzmán C, Lorenzo MA, et al. Laboratory diagnosis of schistosomiasis in areas of low transmission: a review of a line of research. Mem Inst Oswaldo Cruz 2002;97:167-9.

Obregón-Henao A, Gil DL, Gómez DI, Sanzón F, Teale JM, Restrepo BI. The role of Nlinked carbohydrates in the antigenicity of Taenia solium metacestode glycoproteins of 12, 16 and $18 \mathrm{kD}$. Mol Biochem Parasitol 2001;114:209-15.

Oliveira LCM, Ribeiro CT, Mendes DM, Oliveira TC, Costa-Cruz JM. Frequency of Strongyloides stercoralis infection in alcoholics. Mem Inst Oswaldo Cruz 2002;97: 119-21.

Olsen A, van Lieshout L, Marti H, Polderman T, Polman K, Steinmann P, et al. Strongyloidiasis-the most neglected of the neglected tropical diseases? Trans Roy Soc Trop Med Hyg 2009;103:967-72.

Porto AF, Neva FA, Bittencourt H, Lisboa W, Thompson R, Alcantara L, et al. HTLV-1 decreases Th2 type of immune response in patients with strongyloidiasis. Parasite Immunol 2001;23:503-7.

Rihet P, Demeure CE, Dessein AJ, Bourgois A. Strong serum inhibition of specific IgE correlated to competing IgG4, revealed by a new methodology in subjects from a $S$. mansoni endemic area. Eur J Immunol 1992;22:2063-70.

Roxby A, Gottlieb G, Limaye A. Strongyloidiasis in transplant patients. Clin Infect Dis 2009;49:1411-23.

Schaffel R, Nucci M, Carvalho E, Braga M, Almeida L, Portugal R, et al. The value of an immunoenzymatic test (enzyme-linked immunosorbent assay) for the diagnosis of strongyloidiasis in patients immunosupressed by hematologic malignancies. Am J Trop Med Hyg 2001;65:346-50.

Schallig HD, Van Leeuwen MA. Carbohydrate epitopes on Haemonchus contortus antigens. Parasitol Res 1996;82:38-42.

Souza-Atta ML, Araujo MI, D'Oliveira Junior A, Ribeiro-de-Jesus A, Almeida RP, Atta AM, et al. Detection of specific IgE antibodies in parasite diseases. Braz J Med Biol Res 1999:32:1101-5.

Uparanukraw P, Phongsri S, Morakote N. Fluctuations of larval excretion in Strongyloides stercoralis infection. Am J Trop Med Hyg 1999;60:967-73.

Van Doorn HR, Koelewyn R, Hofwegen H, Gilis H, Wetsteyn JC, Wismans PJ, et al. Use of enzyme-linked immunosorbent assay and dipstick assay for detection of Strongyloides stercoralis infection in humans. J Clin Microbiol 2007;45:438-42.

Vervelde L, Bakker N, Kooyman FNJ, Cornelissen AWCA, Bank CMC, Nyame AK, et al. Vaccination-induced protection of lambs against the parasitic nematode Haemonchus contortus correlates with high IgG antibody responses to the LDNF glycan antigen. Glycobiology 2003;13:795-804

Woodward M, Young W, Bloodgood RA. Detection of monoclonal antibodies specific for carbohydrate epitopes using periodate oxidation. J Immunol Methods 1985;78: 143-53.

Younis T, Fahmy I, EI-Wakil HS, Ali NM, Ibrahim A. Attempt to improve the diagnostic efficacy of enzyme-linked immunosorbent technique for the serodiagnosis of cystic echinococcosis. Parasitol United J 2008;1:129-36. 